\title{
NOTE-TAKING OF ENGLISH LESSONS AT TERTIARY LEVEL: A CONTEXT OF BANGLADESH
}

\author{
Farzana Sharmin Pamela Islam \\ East West University, Bangladesh \\ Email:farzanaislam80@gmail.com
}

\begin{abstract}
Note-taking is a common and an important classroom activity. Notes that students create in class while listening to the lectures given by lecturers, or while they review course material, become an important means of learning. It is a general perception of many learners and many of their instructors as well that note-taking is a common manifestation and intuitive skill to have, yet a few considers differently and encourage best practices for better performance. Unfortunately, many students are unaware of its benefits and so fail to appreciate that effective note-taking contributes to a great extent to their learning, and so the importance of cultivating their note-taking skills in course of their education period. This paper based on qualitative analysis provides an overview of how Bangladeshi students follow different strategies to take down notes in lecture sessions at tertiary level. The primary data for this paper has been collected from 35 students' paragraph writing on a topic 'How to take notes in a lecture' in which the students were asked to reflect on their own note-taking strategies, how they get benefit from their notes, and their subsequent retrieval of information from the notes later on. The participants were from a 'Basic English' course as well as from English core courses at a highly rated private university in a metropolitan city in Bangladesh. This case study evolves around four aspects of note taking: firstly, the principal functions of note-taking; secondly, the main strategies students used for note-taking; thirdly, the benefits that the students derive through various approaches to note-taking; and lastly, the initiatives to improve the art of note taking as a successful tool in learning target subject matter. While some of the findings are in line with earlier studies, a few of them have their own uniqueness.
\end{abstract}

Keywords: Note-taking, note-taking strategies, benefits of note-taking, note-taking at tertiary level

\section{INTRODUCTION}

Note-taking is a common and an important classroom activity. Notes that students create in class while listening to the lectures given by lecturers, or while they review course material, become an important means of learning. It is a general perception of many learners and many of their instructors as well that note-taking is a common manifestation and intuitive skill to have, yet a few consider differently and encourage best practices for better performance. Unfortunately, many students are unaware of its benefits, and so fail to appreciate that effective note-taking contributes to a great extent to their learning, and the importance of cultivating their note-taking skills over the course of their education. Reaffirming the multifaceted importance of note-taking, Friedman (2014) mentions that good notetaking practices can lead to efficient study practices, better course outcomes, and improved retention of content beyond a course's conclusion. Notes can be defined as written materials that are commonly drawn from a brief source, such as an oral discussion at a meeting, seminars or a lecture, in which case the notes may be the only record of the event. Note-taking is a form of self-discipline. Moreover, 'note-taking is a central aspect of a complex human behavior' (Wikipedia). The person taking notes must acquire and filter the incoming sources, organize and restructure 
existing knowledge structures, comprehend and write down their interpretation of the information, and ultimately store and integrate the freshly processed material, and the result is a knowledge representation, and memory storage.

However, note-taking is one of the most difficult things as well for a student to do effectively. It can be difficult for students to know what to write down, what information is pertinent, or how to structure their notes so that they can study them in the future. By taking the time to understand why we take notes, how it can be done best way, and how to use them, we may be able to improve our ability to make them truly useful. Notes taken during reading or lectures can be one of the strongest tools a student has in their academic experience (Western Michigan University, no date).

Referring to some dangers of improper note-taking, Boyle (2013) mentions that there are possibilities of missing out the benefit of note-taking if it is not done properly. Unstructured note-taking runs the risk of missing main points of lectures, failure to establish connections among the ideas shared, and interpret the referent to the key constructs presented in the lecture. There may be pages of notes mostly unstructured and recorded haphazardly using multi colored pens, missing out main points. In such cases subsequent use of the notes meaningfully may not also be possible.

Notes taken strategically leads students understand lecture content more fully through activating prior knowledge of the topic, monitoring teacher cues that mark key points to be included in notes, recording novel vocabulary items, and pondering interconnections between lecture points (Boyle, 2013).

This paper based on qualitative analysis provides an overview of how Bangladeshi students follow different strategies to take down notes in lecture sessions at tertiary level.
The primary data for this paper has been collected from a writing task assigned to 35 students. The students were asked to write a paragraph in English reflecting their individual experiences of writing on a topic like How to take notes in a lecture, in which the students were asked to reflect on their own note-taking strategies, how they benefit from their notes, and their experience of retrieving information from the notes later on. The participants were from a 'Basic English' course as well as from English core courses at a highly rated private university in a metropolitan city in Bangladesh. This case study evolves around four aspects of note taking: firstly, the principal functions of note taking; secondly, the main strategies students used for note taking; thirdly, the benefits that the students derive through various approaches to note-taking; and lastly, the initiatives to improve the art of note taking as a successful tool in learning target subject matter. While some of the findings are in line with earlier studies, a few of them have their own uniqueness. An overview of the main functions of and strategies followed in notetaking maybe useful for our discussion.

\section{THE FUNCTIONS OF NOTE-TAKING}

Studies on note taking (Boch \& Piolat, 2005; Boch, 1999; Van Meter et al., 1994) have identified two broad functions of notetaking. First of all, learners take notes to record information and/or to aid reflection. Notes taken are also used as a simple memory aid, similar to a shopping list, or a record of actions, such as a diary. In another sense, note-taking is to build up a stable external memory in a form that can be used easily at a later date (Boch \& Piolat, 2005). Moreover, note-taking is an essential tool in many information-transmission situations. At the tertiary level, note-taking plays a greater role and allows students to gather information from lectures, books, or any other situation that they will later have to consult or use in 
order to successfully complete their academic tasks. Storage methods vary from "copyregurgitate" strategies, which have proven to be effective from a scholastic point of view, to more complex 'reformulation-interpretation' strategies. The frequency of using 'reformulation-interpretation' strategies by students is relatively less (Boch, 1999; Van Meter et al., 1994), probably because this strategy that requires consecutive interpretation of information received either in piecemeal or in a chunk for any reformulation process, if not handled efficiently, is risky: it is more difficult to faithfully reproduce the source information when this information has been reformulated rather than simply transcribed. The use of note-taking for storing transmitted information often overshadows another important role - reflection. Notetaking is an effective information-processing tool that is commonly used both in daily life and in many professions (Hartley, 2002). In line with the studies mentioned above, the student-participants of this study have indicated that they use the notes taken during lectures as an aid to prepare comprehensive notes for examination purposes. They have also noted that they do not remain limited to the notes taken during classroom lectures; they also use online sources when they prepare comprehensive notes for examinations or for assignments. It is not very explicitly evident although the participants utilize the notes taken during classroom lectures for a range of 'intellectual processes, such as making judgments, resolving issues, and making decisions' (Boch \& Piolat, 2005), and also it is not evident from the data how much do these students use the notes for such intellectual enhancement. But it is evident that they use the notes as a source of examination prediction. That they take notes as first draft and also as an instrument to save time in realtime thought processing is also consistent to Cary and Carlson's (1999) study. To my disappointment, there is almost no provision at the universities here in Bangladesh to develop this useful skill of note taking. Had there been a culture of developing this skill among the students, they could have been able to acquire the two-fold functions: (1) taking notes to stabilize the knowledge to be acquired and reproduce during 'course question' type examinations and (2) taking notes to effectively resolve problems.

\section{DIFFERENT STRATEGIES OF NOTE- TAKING}

The research (Foulin, 1995; Piolat, 1982, cited in Piolat et al. 2005) shows that the average writing speed of a student is around 0.2 to 0.3 words per second, whereas a lecturer speaks at a rate of around 2 to 3 words per second. Unless everything is said at a dictation speed, or students develop exceptional shorthand skills, teachers rarely speak slowly enough for students to write down everything that is said. As a result, students intuitively develop their processes and methods that allow them to record the content of the lectures. From the collected data, it has emerged that the students use various kinds of linguistic processes and mechanical devices, while taking notes, such as the use of abbreviations, truncating long words etc. In spite of lot of homogeneity among them, the participants shared their individually unique experiences of notetaking. For example, one of the participants has noted,

"...usually I write down word or phrases (if necessary a full sentence) ... keep a gap in between the key words so when the instructor is giving further explanation of that word or phrase I can write down the detail. If the lecture involves a story then I write specific words that can make me remember a scenario w/o any sentence and put an ">" after each key word/phrases to maintain chronology...I choose the words that occur frequently and has unique 
information to it. Sometimes I feel the need to add subjects and objects to further clarify the information for the later use. ..."

Justifying their note-taking strategies another participant has shared their practice:

"Most of the time, I took [sic] notes along the margins of my literature texts, connecting to the corresponding lines/paragraphs. ... If the lecture includes something out of the text, such as relevant theories, attributes or definitions, I used to write them in the notebook, but I took notes of keywords, names, small definitions, and made charts and diagrams of information as much as possible. It required less time and space for writing and I could focus more on listening, which is important to me as I am mostly an auditory learner."

Referring to a varied strategy of notetaking adopted by students, a participant explains that his note-taking depends on who teaches and what the teacher teaches:

"My strategy of writing the lecture usually depends on the course and the faculty. If the teacher provides the necessary materials then I usually write just the significant points which are necessary for my understanding the lecture. But usually I prefer to write the whole lecture. It helps me to understand better my studies later on."

However, another student referring to his post note-taking activity, has shared a different strategy,

“... as we have a limited time for taking notes in class room I don't usually write full sentence and try to use short form of words. ...I usually make a certain gap when a teacher is explaining something and just write down a single word that I can trigger out the explanation, later on I add the explanation in an easy way."
It has also been evident in this study that note-takers are very keen to take note of the discourse markers in a speaker's text that signal, more or less explicitly, the importance of what is being said, which have an extensive influence on the total volume of notes taken. They give more importance to the points presented both orally and written on the board.

Indicating the changes in the note-taking strategies due to the emergence of technology, some participants have mentioned that they prefer to use their laptops and mobile phones for note-taking purposes. As a result of this digitalization of note-taking, some students tend to adapt Boyle's (2010) template of notetaking. What some mobile phone users do is that they go for recording the lecture, rather than taking note which involves skimming and scanning of the lecture.

From students' perception of note-taking, it has been evident that students prioritize their note-taking through some indicators which influence their note-taking styles also. For example, writing on the board, which is a very powerful indicator and students assume that it's extremely important and likely to be included in their examination. Another indicator is dictation, and when the teacher is dictating the information, they are expected to deliver slowly. In addition, students also look for an indicator in order to take notes, when the title of a particular section or lists of information are likely to be written on the board. Sometimes definitions and catchy phrases are also noted by the students even if they do not understand them. Students also look for signposts, which organize and structure the lectures, expressions such as "firstly"/secondly" or "first question"/"second question". The study also indicates that the students also take notes with special attention while course instructors give briefing before any examination. All these 
indicators are very much attached to written communication.

\section{THE BENEFITS OF NOTE-TAKING}

That note-taking contributes to the students' cognition process has been observed among the participants. Kiewra (1989, cited in Carrell, 2007, p.2) has made similar observation that note-taking is valuable for at least two reasons. First, note-taking helps lecture learning by activating concentration mechanisms and engaging the learner's cognitive processes of coding, integrating, synthesizing, and transforming aurally received input into a personally meaningful form. Second, note-taking is considered as beneficial because the notes taken serve as an external repository of information that permits later revision and review to stimulate recall of the information heard. The findings of the present study also has some similarities with Dunkel's (1988, p.278) study that maintains, that note-taking is perceived by examinees as a strategy that facilitates remembering the lecture content. While there are some commonalities among the students regarding the benefits of note-taking and the strategies they follow during note-taking, at micro level they also differ.

For instance, one student has pointed out that they depend on post lecture reading to complete their notes.

"... actually I try to write my notes from the lecture as a phrase or single sentences, sometimes they become jumbled and when I miss them by any chance, I put a gap and rewrite it by myself after reading the main material, and sometimes I do brainstorming during the lecture time."

Some other students have mentioned of their preference for amalgamation of lecture content, their own thoughts and observations.

“... I myself try to capture the exact words of each and everyone's lecture and then I put some of my own thoughts and observation about that particular topic. Blending this two things and then write is easier for me to captured [sic] the whole topic."

Still another group of students uses notes taken during lecture as clues and to activate and recollect lecture content.

"Quickly remembering the session with the trigger words so I won't have to go scan the whole lecture again. Also I try to add the last bit of information so in the end I don't get lost while recalling the lecture bits."

Similar kind of experience has been shared by another student,

"... The benefit is I can recall the lectures seeing the key points as I always make circle or give signs on my lectures where it is more important. Moreover it is easy to understand and get it clearly even after two weeks."

In general, students take notes in order to record information that they may need to learn later on. However, the result of taking notes is much more than the production of a passive "external" information store, as the note taking action itself is part of the memorization process and results in the creation of a form of "internal" storage (Kiewra, 1987). The student-participants of the study have perceived note taking in a different terminology. They take note-taking as a kind 'emptying memory' - meaning releasing a part of their biological memory. So they feel that note-taking reduces the pressure on the working memory of the students, and helps them to resolve difficult problems.

\section{NOTE-TAKING AS A FACILITATING LEARNING TOOL}

The participants have indicated a complete alignment with what Kiewra et al. (1995) has observed in their study. Taking notes is not the ultimate achievement for a 
tertiary student, rather it is a means of achieving other academic goals. Note-taking can have a significant influence on learners' comprehensibility of a lesson only when the follow up steps are maintained. Note-takers are assumed to re-read their notes as many times as necessary for them to learn their content. They need to go through their notes, read them, highlight the important parts and summarize them. They also need to connect their taken notes with handouts provided by the teacher and the textbooks. The more the information learning process involves understanding and transformation operations, the greater the intensity and effectiveness of the learning process.

One of the most important reasons of note-taking for students is to develop an ability to link with examinations in which getting high grades is the first and foremost goal of every student. Students carefully analyze teachers' lecturing strategies like repetition, writing on boards, and make prediction of getting them in the examinations.

"... By writing down the note it helps me a lot. I get a beforehand idea about the topic. Since I make the note, I get introduced to it and it helps me to understand the topic more easily. It also shortens the loss of time before the exam. Notes also make studying easy. In easier words, notes are a blessing before the night of an exam. It shows that I am well prepared for the exam beforehand."

Thus, it is better to highlight notes than to simply read them, and better again to summarize them (re-write them) than highlight them.

\section{CONCLUSION}

Note-taking being a very common academic activity to enhance learning outcome, students use different strategies to reap different benefits. To maximize the benefits from note-taking, students should be encouraged to develop better note-taking strategies and also the skill of utilizing notes they have already taken during lectures. As most of the universities in Bangladesh lack the facility of developing this study skill, programs to teach and enhance this important academic study skill can be introduced at student learning units or counseling centers for improving students' academic proficiency level.

\section{REFERENCES}

Boch, F. \& Piolat, A. (2005). Note Taking and Learning: A Summary of Research, The WAC Journal, 16, pp. 101-113. Retrieved from https://wac.colostate.edu/journal/vol16/bo ch.pdf. Retrieved on 20-2-17.

Boch, F. (1999). Pratiquesd'écriture et de réécriture à l'université. La prise de notes, entre texte source ettextecible [Writing and Rewriting at University. Example of Note Taking]. Paris: Presses Universitaires du Septentrion.

Boyle, J. R. (2010). Strategic note-taking for middle school students with learning disabilities in science classrooms. Learning Disability Quarterly, 33(2), pp.93-109. doi:10.1177/0022219410371679.

Boyle, J. R. (2013). Strategic note-taking for inclusive middle school science classrooms. Remedial and Special Education, 34(2), pp.78-90.

Carrell, P. L. (2007). Note-Taking Strategies and Their Relationship to Performance on Listening Comprehension and Communicative Assessment Tasks, TOEFL Monograph, MS-35, Princeton, NJ: Educational Testing Service.

Cary, M. \& Carlson, R. (1999). External support and the development of problem-solving routines. Journal of Experimental Psychology: Learning, 
Memory, and Cognition, 25(4), pp. 1053-1070. Retrieved from http://psycnet.apa.org/index.cfm?fa=buy .optionToBuy\&id=1999-05966-016.

Retrieved on 12-3-2017.

Dunkel, P. (1988). The Content of L1 and L2 Students' Lecture Notes and Its Relation to Test Performance. TESOL Quarterly, 22, pp. 259-281.

Friedman, M. (2014) Notes on Note-Taking: Review of Research and Insights for Students and Instructors, Harvard Initiative for Learning and Teaching, Harvard University, http://hilt.harvard.edu/files/hilt/files/not etaking_0.pdf. Retrieved on 22-3-2017.

Hartley, J. (2002). Note taking in nonacademic settings: a review, Applied Cognitive Psychology, 16(5) pp.559574.

Kiewra, K. A., Benton, S. L., Kim, S., Risch, N. \& Christensen, M. (1995). Effects of note-taking format and study technique on recall and relational performance. Contemporary Educational Psychology, 20, pp. 172-187, https://bmri.korea.ac.kr/file/board_data/p ublications/1277274119_1.pdf. Retrieved on 11-3-2017.

Kiewra, K. A. (1987). Note taking and review: The research and its implications.
Journal of Instructional Science, 16, 233249.

Piolat, A., Olive, T. \& Kellogg, R. (2005). Cognitive Effort during Note Taking. Applied Cognitive Psychology, 19, pp. 291-312. Retrieved from http://centrepsycle-amu.fr/wpcontent/uploads/2014/01/POK2005ApplCogPSy.pdf. Retrieved on 21-22017.

Van Meter. P., Yokoi, L. \& Pressley, M. (1994). College Students' Theory of Note-Taking Derived From Their Perceptions of Note-Taking, Journal of Educational Psychology, 86, pp.323-338. doi: $\quad 10.1037 / 0022-0663.86 .3 .323$. Retrieved from https://www.researchgate.net/publication/ 232516387. Retrieved on 21-2-2017.

Western Michigan University (no date). Note Taking Techniques, Retrieved from https://wmich.edu/asc/files/NoteTakingT echniques.pdf. Retrieved 19-2-2017.

Wikipedia, (no date). Note-taking, Retrieved from https://en.wikipedia.org/wiki/Notetaking. Retrieved on 21-2-2017. 